\title{
DGNB BUILDING CERTIFICATION COMPANION: SUSTAINABILITY TOOL FOR ASSESSMENT, PLANNING, LEARNING, AND ENGAGING (STAPLE)
}

\author{
RENATE SKOVGAARD MØLLER, MICHAEL K. RHODES \& TINE STEEN LARSEN \\ Aalborg University, Department of Civil Engineering, Denmark.
}

\begin{abstract}
In the construction industry, the popularity of sustainability and its benefits have been on the rise in recent years. Alas, with various building sustainability assessment schemes on the market, there is still no single general method for a comprehensive and inclusive design and building process for sustainable buildings. The literature describes several barriers of entry preventing actors in the industry from seeking sustainability certifications and prioritizing design methods, supporting sustainability in greater numbers. In the newly developed tool, "DGNB building certification companion: Sustainable Tool for Assessment, Planning, Learning, and Engaging (STAPLE)", a new Excel-based, interactive, and iterative education focused platform is introduced, intended to engage dialog among stakeholders, building owners, and decision makers, and the assigned group team leaders, based on the five DGNB topics. In order to establish common levels of knowledge, terminology, and understanding for proper interdisciplinary discussions, which would result in suitable and timely decisions, personal and professional development is enabled by imbedded educational documents in multiple formats throughout the tool as plain-language, easily digestible summaries of various topics regarding sustainability and the DGNB certification scheme. The identified barriers are described in the tool followed by a solution to overcome them. The tool, tested at multiple stages of development and moulded by many individuals both within and outside of the sustainable building industry, has shown to achieve the primary goals of assessment of individual's current knowledge, educating through multiple stages and formats, and the inspiring of conversation among team members through a graphical display of opinions. Based on user feedback, the conclusion was that this is a desired product on the market. This new approach is expected to dramatically reduce misunderstandings, conflicts, and mistakes during a sustainable design process, helping the design team plan a project to possibly obtain the highest DGNB score if desired and properly documented.

Keywords: building sustainability assessment schemes, DGNB, integrated design process, sustainability, sustainability certifications, sustainability certification companion tool.
\end{abstract}

\section{INTRODUCTION}

Rooted in the belief that: 'To pursue sustainability is to create and maintain the conditions under which humans and nature can exist in productive harmony to support present and future generations.' [1], sustainability remains a priority interest of many organizations and groups around the world. As a significant contributor to pollution and resource consumption [2], the global building and construction industry faces several challenges to maintain the same level of quality and keep up with the modern day demands, whilst living up to the worldwide sustainability aspirations.

There are several initiatives and strategies to improve these issues both globally and locally, such as the development of new building standards. In Denmark, the Building Regulations are relatively stringent, encouraging healthy indoor environment, lowered energy consumption, and safe building practices [3]. Sustainable building certifications and rating systems is another method to achieve lowered negative environmental, economic, and social impact by promoting and encouraging sustainable design. While there are multiple sustainable building certifications around the world, DGNB, developed by Deutsche Gesellschaft für 
Nachhaltiges Bauen, or in English, German Sustainable Building Council, is the process often used in Europe, and adapted and modified in Denmark to match the current national building regulations [4]. However, it is worth noting that DGNB remains a voluntary option and is not part of the current building regulations in Denmark.

DGNB is a sustainable building assessment system, based on a weighted list of indicators, which, if completed through building design, award points in various categories, if properly documented and awarded by a third-party auditor. Sustainable design principles are promoted such as Responsible procurement and Waste management. Uniquely, economy is viewed as a resource and Life Cycle Cost calculations are also included in the assessment. Furthermore, social sustainability is equally prioritized with concepts of User safety, Indoor Air Quality and Access for all. This makes DGNB one of the most inclusive in regards to the different aspects of sustainability.

If properly documented and small adjustments in design and construction were made to account for the DGNB process, many buildings constructed may be near to qualifying for the lowest certificate level of silver under the Denmark modified DGNB scheme $[3,5]$.

According to Denmark Statistics [6], in 2015 construction was completed on over 5.5 million square meters of all building types in Denmark. Yet, according to the Green Building Council Denmark [7], there are only 30 DGNB certified buildings. Of those 30, 20 are office and administrative buildings. Thus, there appear to be many barriers to obtaining a certification. Several of them include:

- the cost of the certification and auditing;

- paperwork man-hours;

- additional cost required in the construction of the building;

- access to databases or the resources to generate the database;

- lack of basic understanding and the complexity of DGNB;

- and lack of general knowledge of the DGNB system [8].

Because of these barriers, it also appears that the largest firms have a significant advantage over smaller firms working on smaller projects. Though the largest projects may garner the most attention, the majority of the building stock in Denmark are homes and other smaller buildings, often completed by small or middle-sized companies, indicating a large potential market [9].

STAPLE, a companion to the DGNB International CORE 14 criteria manual, introduced in this paper is intended to help reduce some of the above-mentioned barriers.

\section{UNDERSTANDING STAPLE}

STAPLE (Sustainable Tool for Assessment, Planning, Learning, and Engaging) is an Excelbased interactive and iterative, education based platform intended to engage dialog among the Stakeholders \& Decision-Makers and the assigned group Team Leaders, which are based on the five DGNB topics:

1. Economic Quality (ECO)

2. Environmental Quality (ENV)

3. Process Quality (PRO)

4. Sociocultural and Functional Quality (SOC)

5. Technical Quality (TEC) 
STAPLE assesses the user's knowledge of sustainable buildings through several confidential questions, not revealed to others at any point when they first work with the tool. Based on the response and the level of knowledge, the tool provides additional educational material. At each stage of the tool, the user is provided plain-language easily digestible summaries of each Topic and Criterion. This is provided using multiple formats (PDFs, summary and bullet lists) and in different locations throughout the tool to aid in the learning process. Using different methods of input for differentiation, the users are prompted at two levels. The top-level input helps the user prioritize the DGNB five Topics. Each Topic is broken into Criterion, a tertiary level of DGNB. Each user is provided Topic-specific Criterion statements, a summary of the Criterion and asked to provide their understanding of the importance of that statement with regard to the other statements of that Topic. The assessment of the user input is provided graphically to encourage dialog. Visually seeing the difference of opinions among the users is intended to engage the users in discussion. The planning stage of the tool relies on the user's input of Confidence in Completion or their opinion of what level a specific activity might be completed for the project. This results again in a graphical output of the user's responses to engage the users in further dialog. Finally, with all input from all of the users and an estimation of DGNB indicator weighting, the planning of the project can be driven by an arranged list of indicators. If the list is followed, the highest concerns of the users will be met while possibly obtaining the most amount of DGNB points if properly documented.

The tool, tested at multiple stages of development and molded by many individuals both within and outside of the sustainable building industry, have shown, through their feedback that this is a desired product in the market. It achieves the primary goals of assessment of individual's current knowledge, educating through multiple stages and formats, the inspiring of conversation among team members through a graphical display of opinions, and helping the design team plan a project to possibly obtain the highest DGNB score.

\subsection{Design process}

According to various sources, the earlier sustainable strategies are considered and implemented into a project, the more successful the outcome [10]. This calls for a different approach as opposed to the conventional design process, Fig. 1, with a sketching phase carried out by the architect, a design phase in which an engineer gets involved, and an execution phase, in which contactors are appointed.

While there are several interpretations of an Integrated Design Process, as established by Camilla Brunsgaard, Mary-Ann Knudstrup, and Per Kvols Heiselberg in the paper Experiences from the Design Processes of the First 'Comfort Houses' in Denmark, The Integrated Design Process, Architecture \& Design, Aalborg University (AOD IDP), which is an approach developed as a method for architecture students at Aalborg University, Civil Engineering in Architecture \& Design, will be considered for STAPLE, as illustrated in Fig. 2 [11].

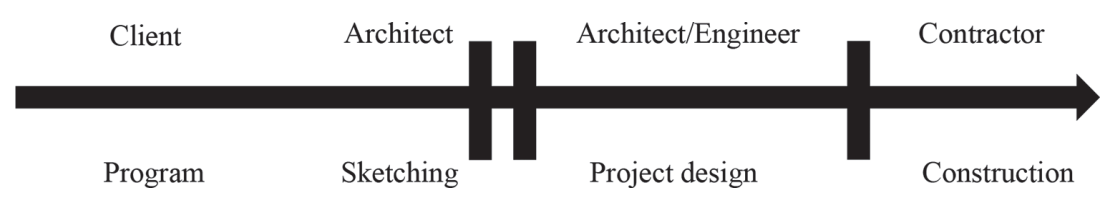

Figure 1: A traditional design process - a linear approach [11]. 


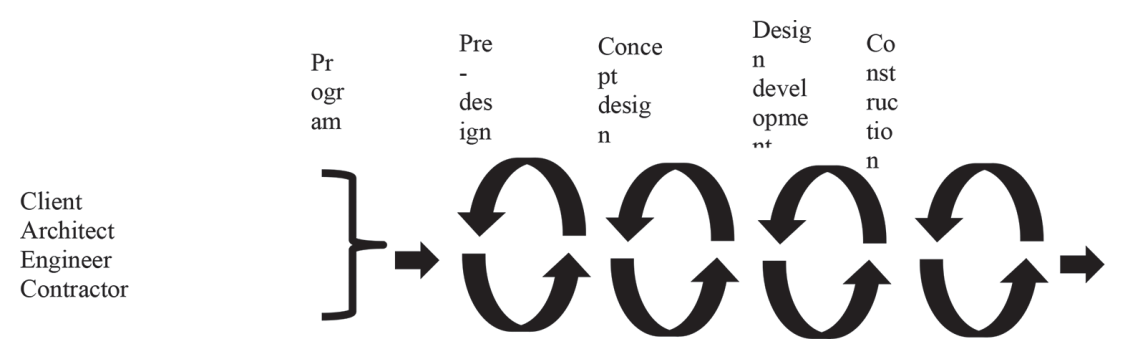

Figure 2: The Integrated design process - an iterative approach [11].

By repeating a cycle of design proposals, discussions, early changes, and subsequent new proposals, a design embodying the input and demands of all participants while fulfilling the overall project criteria, gradually emerges. STAPLE is suitable for an Integrated Design Process, as the live feedback generated by it allows the user to work in iterations and use the tool throughout the design process in various stages of the project.

\subsection{STAPLE introduction}

The education is intentionally provided in many ways. It is aimed at breaking the system down into plain language and small but manageable pieces.

The educational material is available throughout the tool as embedded PDFs that are always available to the user through the use of the STAPLE navigational bar that resides on the right side of the screen by default. Secondly, each user is then asked questions about their basic knowledge of sustainable buildings and the DGNB system. If the user is authentic with themselves and the tool, they may or may not be required to open some of the embedded educational material PDFs.

Third, the material is also broken down and provided in statements for each Topic. Each Criterion statement is presented as a plain language summary of comments that appear as a popover for a quick overview of what is entailed within each statement.

Once all input has been provided, the Stakeholders \& Decision-Makers (SDM) are provided with results that compare their responses to the design Team Leaders (TL). SMD are intended to be building owners and their representatives, client consultants, and alike. TLs often specialists within their respective fields, or professionals in charge of certain aspects of sustainability within a project team. Within STAPLE, there is one SDM and five TLs - each responsible for one of the five Topics within the DGNB. This is intended to create discussion between the groups. Providing independent input into the tool, an open discussion is encouraged to contemplate the differences of opinions. Having learned more about the system through the STAPLE process, the users may gain significant insight into their own understanding but also the understanding and knowledge of those working on the project team. This connection to the knowledge should help the communication of the team throughout the design process. 


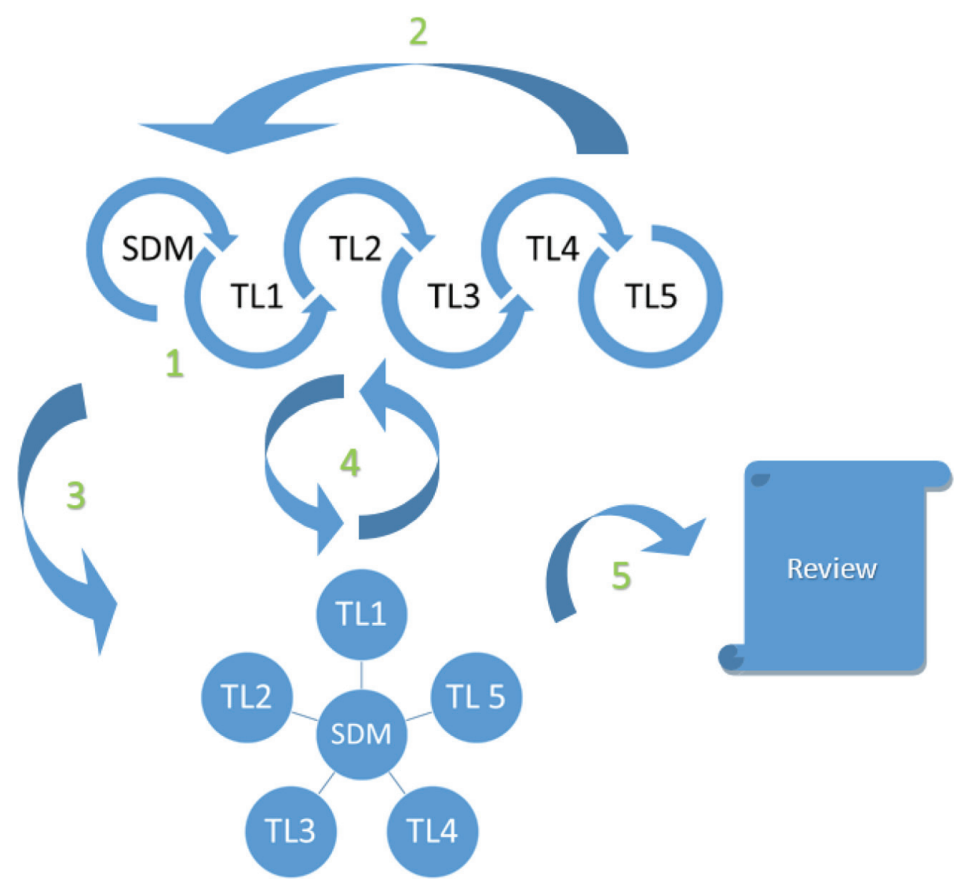

Figure 3: The intended flow of STAPLE sharing.

1. The Stakeholder and Decision Maker (SDM) starts up the tool, sets up PIN codes, determines the initial desired level of certification (if above Silver), and files out the respective sheets before saving the tool, exiting and passing it on to the Team Leaders (TLs).

2. Once the five TL input sections have been filled out, the tool would return to the SMD for review.

3. The SDM and all TLs discussing and reviewing the results.

4. The iterative process of several rounds of adjustments to the design until a satisfactory result has been achieved.

5. The final selection of STAPLE outcomes is reviewed by the project team members.

The final part or the advanced portion of the tool are prioritized lists of indicators, DGNB established design parameters needed to complete in order to achieve certification, based on the user input and an overview analysis of the possible DGNB certificate level. The analysis, based on either the Stakeholders \& Decision-Makers or Team Leaders' Confidence in Completion (CiC) values and the DGNB estimated weights, a determination of possible certificate level is projected. The $\mathrm{CiC}$ value is the user's estimation of the level to which a certain design goal can be accomplished. Maximum amount of points possible in DGNB are awarded for a $100 \%$ completed criterion. The lists can be provided in several ways including the estimated indicator share of the total score if the DGNB weights are included. Otherwise, the user may create multiple lists depending on what weighting they would like to include in the system.

Through the focused interaction with STAPLE, commitment to reading the provided educational materials in all formats, and candid inputs, STAPLE has the ability to significantly reduce some of the barriers to entry into the DGNB Sustainable Building Certification 
system. The tool was tested many times by multiple people with a wide range of backgrounds. Their feedback is an indicator that this tool is helpful and can create an impact in the market if properly used.

STAPLE improves the user's general knowledge of the DGNB System and reduces the complexity to allow more individuals to be involved and learn about the process. STAPLE is just the first step in engaging a much wider audience to the understanding and implementation of the DGNB Building Certification System in many more projects.

\subsection{DGNB system}

Deutsche Gesellschaft für Nachhaltiges Bauen, DGNB, or the German Sustainable Building Council's system of sustainable building certification is based upon a hierarchal chain of information. At the top of the systems' chain are the five primary topics and one secondary topic. The five primary topics are the focus of this paper as the sixth topic, Site, does not influence the scoring and determination of certificate level. Under the Topic are the Criteria Groups; within each Criteria Group is a collection of Criterion and their associated Indicators. Each Indicator is a requirement that must be fulfilled to obtain the checklist points.

Although the DGNB assessment scheme has been investigated for the purpose of developing STAPLE and the math behind the evaluation matrix has been analyzed, the reasoning behind the DGNB weighting factors is unknown. The recreated matrix is, therefore, solely an estimation.

\subsubsection{DGNB Performance indices}

Performance Indices are the method of evaluation developed by DGNB to rate each building. To elaborate further, there are two parts of the performance index that must be satisfied to qualify for a certificate.

The first is the Minimum Performance Index (MPI). This is the requirement of each and all Topics. Accordingly, to be considered for a Silver certificate, all Topics must receive at least $35 \%$. The second part of the qualification is the Total Performance Index (TPI), which is the overall requirement. At Silver, at least $50 \%$ of the total score must be awarded. If only one Topic does not qualify but the TPI is achieved, a certificate will not be awarded [12].

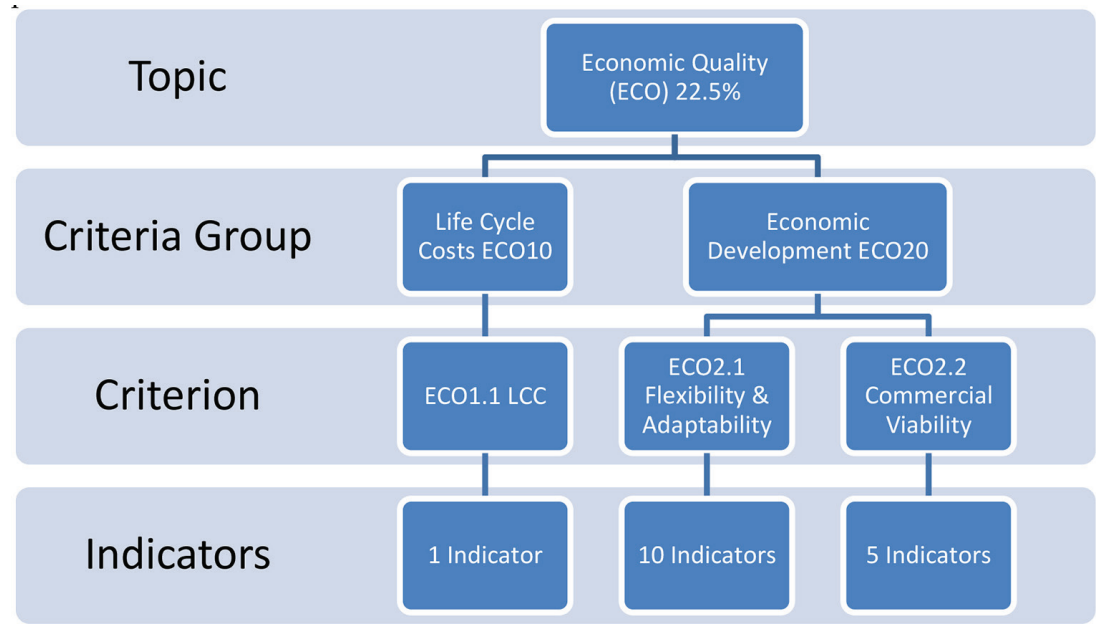

Figure 4: DGNB Topic hierarchy [4]. 


\subsection{STAPLE user input}

The five Topics within the system of sustainable building certification developed by DGNB have been assigned a weight, $22.5 \%$ to four Topics and 10\% to the fifth Topic for a total of $100 \%$. The reasoning behind this weighting is uncertain. This weight is their opinion of each Topic importance. In STAPLE, for input from the user, their opinion is desired and not influenced by the DGNB system. Therefore, before user input, the base value for all five Topics are equal or $20 \%$.

For this project, there are five Topics. The user prefers each Topic but it is not clear to what percentage. For this reason, a pairwise comparison of the five Topics was made using the Analytic Hierarchy Process (AHP) as developed in the 1970's by Thomas Saaty [13]. Ten Pairwise comparisons of the five Topics are needed. Because of the limitations of AHP, it will only be used for the five Topic comparisons.

The Stakeholders \& Decision Makers (SDM) and each of the Team Leaders (TL) are asked to compare the five Topics via the ten statements. The user is asked to slide the slider to a position that agrees with their opinion. When the slider is at the left, the left Topic is most heavily favored and the opposite when the slider is on the right. When the sheet is reset, the sliders are randomly placed on either the left or the right of the selection as to not influence the user. The right column provides feedback to the user regarding their selection. The explanation corresponds directly with the slider input. A consistency ratio is calculated concurrently with the user input.

In this application of the AHP, the deviation used in STAPLE is acceptable as it allows and encourages magnified differences between the Stakeholders \& Decision-Makers and Team Leaders' inputs. If the Stakeholders \& Decision-Makers place significant emphasis on the economics of the project yet all the Team Leaders are different, it will be visually obvious and may encourage discussion, one of the primary goals of the tool.

In addition, as the Team Leaders, the users are asked to provide a Statement Importance percentage for each of the provided statements within the five DGNB Topics that should amount to a total $100 \%$. This is to indicate which statements the user believes are more important and is done through direct input.

The Input Comparisons look at the recorded Statement Importance (SI) from each Team Leader (TL) and the Stakeholders \& Decision Makers (SDM). Both the Stakeholders \& Decision-Makers as well as the Team Leaders were required to provide their opinion on the same statements. Each Team Leader is only required to answer Topic-specific statements while the $\mathrm{SDM}$ is required to answer all of the statements.

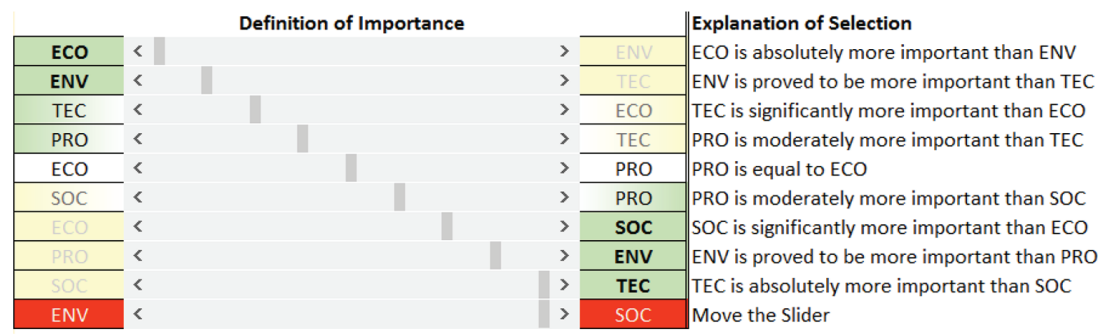

Figure 5: Pairwise user input in STAPLE. 


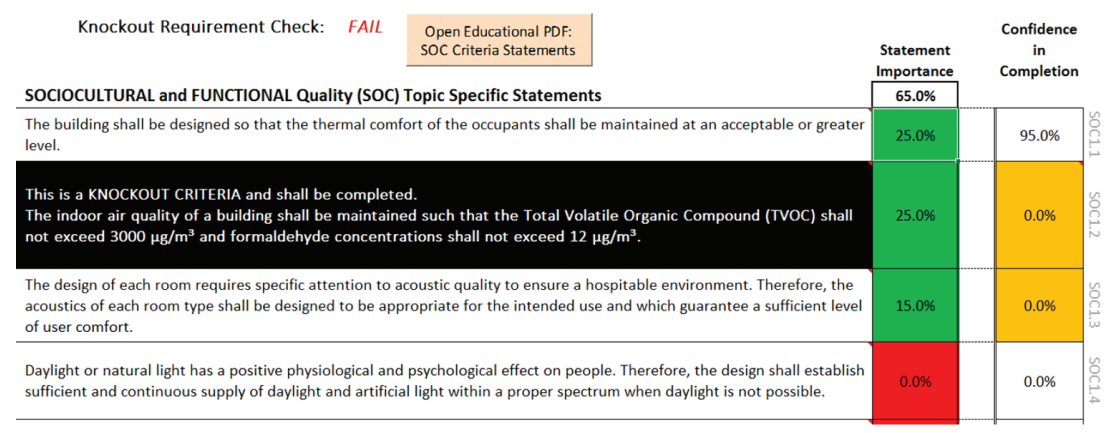

Figure 6: STAPLE Team Leader Input with Statement Importance (SI) and Confidence in Completion $(\mathrm{CiC})$.

Then the Stakeholders \& Decision-Maker was required to input a Confidence in Completion $(\mathrm{CiC})$ for each Topic while the Team Leaders were required to provide a detailed input for each Criterion. Some CiC values have been set minimum limits, according to the DGNB requirements.

\subsection{STAPLE output}

DGNB Indicator weighting is required to estimate a score and the associated list of indicators. The Stakeholders \& Decision-Makers provide a ranking of the five Topics with a pairwise AHP comparison. This is the first sorting of all the Indicators. Two lists are provided. The first list is based on the Team Leaders' input while the second is based on the Stakeholders \& Decision-Makers. With the DGNB Indicator weight or share of the total score, the Stakeholders \& Decision-Makers/Team Leaders' CiC is applied. This is then considered the adjusted indicator weight and will be used to fulfill the requirements of the Minimum Performance Index (MPI) and Total Performance Index (TPI) as described earlier.

The sorting begins with the highest Stakeholders \& Decision-Maker's ranked Topic. The highest ranked is filled with adjusted indicators until the minimum level for the requested certificate level is achieved. Once filled, the sorting continues to the second-ranked Topic to complete. This continues until all five Topics are completed. The higher the desired certification class, the more adjusted indicators are required. Once each of the Topics has enough adjusted indicators to complete the MPI, the Total Performance Index is investigated.

The sum of the indicators used to complete the Topic is collected and compared to the desired certificate level's TPI. If the TPI is not met, additional indicators are needed. The sort selects adjusted indicators with the highest total share from the list of indicators not already used to complete the Topics. Adjusted indicators are added until the TPI is obtained. If the TPI is not possible because of low $\mathrm{CiC}$, all indicators will be shown.

For each Stakeholders \& Decision-Makers and Team Leaders' List of Indicators, an output similar to that in Fig. 6 is provided. At quick review to the right side, the user can assess if the desired level of certificate is possible. The Estimated TPI is determined by summing all the adjusted Indicator's share of the total. This is then presented and compared to the desired certificate. To the right of the TPI estimate is the certificate, which that portion of the score would qualify. 


\begin{tabular}{|c|c|c|c|c|c|c|c|}
\hline & \multicolumn{5}{|c|}{ Team Leader Estimated Total Performance Index } & \multirow[b]{3}{*}{ Desired Certificate: } & \multirow[b]{3}{*}{ Silver } \\
\hline Estimated: & \multirow{2}{*}{\multicolumn{2}{|c|}{$\frac{75 \%}{50 \%}$ Gold }} & & \multicolumn{2}{|c|}{ Performance Ratio, Est/Min: } & & \\
\hline \multirow[t]{3}{*}{ Minimum: } & & & & $=75 \% / 50 \%=$ & 1.50 & & \\
\hline & \multicolumn{5}{|c|}{ Team Leader Estimated Topic Minimum Performance Index } & \multirow{5}{*}{ Possible Certificate: } & \\
\hline & TEC & ECO & PRO & $\mathrm{SOC}$ & ENV & & \\
\hline Estimated: & $98 \%$ & $75 \%$ & $98 \%$ & $66 \%$ & $73 \%$ & & Gold \\
\hline Minimum: & \multicolumn{5}{|c|}{$35 \%$} & & \\
\hline $\begin{array}{r}\text { Estimated } \\
\text { Certificate: }\end{array}$ & Platinum & Platinum & Platinum & Platinum & Platinum & & \\
\hline
\end{tabular}

Figure 7: STAPLE Example Estimated Performance Index (Silver).

\begin{tabular}{|c|c|c|c|c|c|c|c|}
\hline \multirow{3}{*}{ Estimated: } & \multicolumn{5}{|c|}{ Team Leader Estimated Total Performance Index } & \multirow[b]{3}{*}{ Desired Certificate: } & \multirow[b]{3}{*}{ Platinum } \\
\hline & \multirow{2}{*}{$\begin{array}{ll}75 \% \\
80 \% \\
\end{array}$} & \multirow{2}{*}{\multicolumn{2}{|c|}{$\begin{array}{l}\text { Sold is possible, Does Not } \\
\text { Meet Desired Certificate Level }\end{array}$}} & \multicolumn{2}{|c|}{ Performance Ratio, Est/Min: } & & \\
\hline & & & & $=75 \% / 80 \%=$ & 0.94 & & \\
\hline & \multicolumn{5}{|c|}{ Team Leader Estimated Topic Minimum Performance Index } & \multirow{5}{*}{ Possible Certificate: } & \\
\hline & TEC & ECO & PRO & SOC & ENV & & \\
\hline Estimated: & $98 \%$ & $75 \%$ & $98 \%$ & $66 \%$ & $73 \%$ & & Gold \\
\hline Minimum: & \multicolumn{5}{|c|}{$65 \%$} & & \\
\hline $\begin{array}{r}\text { Estimated } \\
\text { Certificate: }\end{array}$ & Platinum & Platinum & Platinum & Platinum & Platinum & & \\
\hline
\end{tabular}

Figure 8: STAPLE Example Performance Index (Platinum).

To the right of the estimated possible certificate for the TPI is a performance ratio. This helps determine how well the TPI is performing compared to the desired level. This is helpful in determining how much effort might be needed for the next level certificate.

Below the TPI information is the MPI for each Topic. Similar to that of the TPI, each Topic's adjusted Indicators are summed based on the share of the Topic weight. This is concisely presented. The MPI for the desired certificate is presented. The final options shown are the possible certificate level for each Topic.

For this example, the Total score is the limiting factor. If the desired level is changed to a level that is not possible, the table will update. Figure 7 shows that the table provides a visual clue that this certificate level does not qualify by marking which element is not sufficient.

\subsection{Indicator Relative Power Ranking}

STAPLE has five modifiers from the users:

1. Stakeholders \& Decision-Makers Topic Ranking Percentage

2. Stakeholders \& Decision-Makers Criterion Group Confidence in Completion

3. Stakeholders \& Decision-Makers Criteria Statement Importance

4. Team Leaders Criterion Confidence in Completion

5. Team Leaders Criteria Statement Importance

The analysis of the DGNB System discovered the Indicator weight as a share of the total score.

These six mutually exclusive weight and modifiers can be combined to modify the rank of each criterion. If the DGNB weight is included, the detail increases to the indicator 


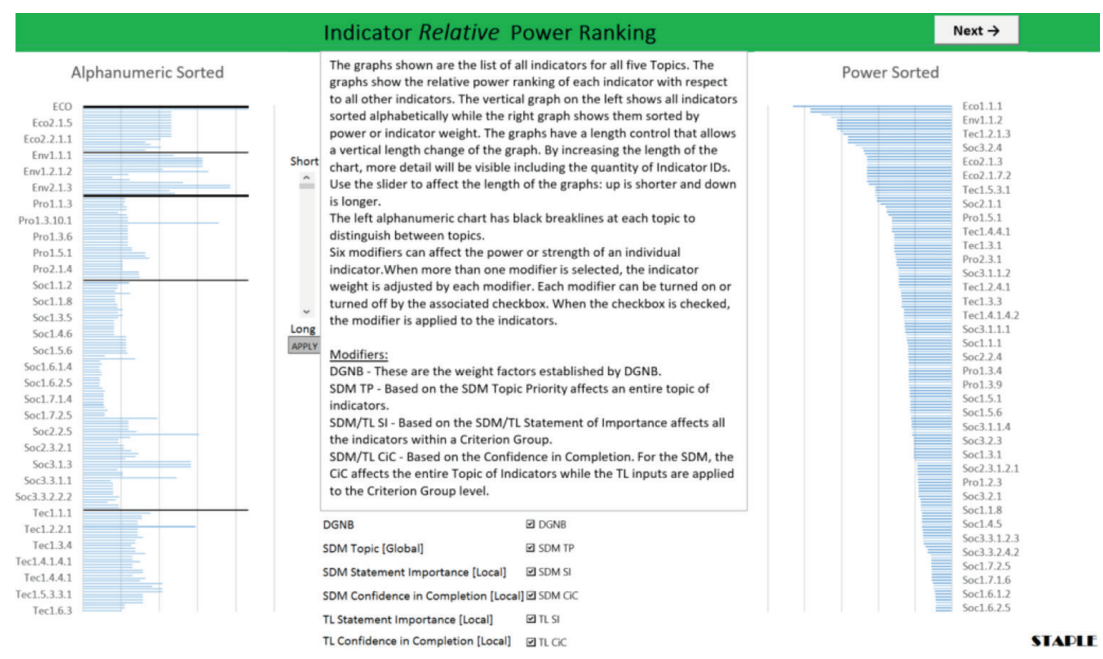

Figure 9: Indicator Relative Power Ranking, STAPLE results, screenshot.

level. The Indicator Relative Power Ranking allows the user to view the list of Indicators sorted in two ways. The first list is alphanumerically sorted with ECO1.1 shown first and indicators in TEC shown last. The second list is sorted by relative power. Below, an illustration of this is provided. The user is also given explanation and guidance in order to interpret the results.

\section{CONCLUSION}

An excel-based tool, named STAPLE (Sustainable Tool for Assessment, Planning, Learning, and Engaging) was initially developed and is intended to assist various project team members in decision making and work-sharing process, to facilitate the Integrated Design Process and to encourage and promote discussions throughout the project phases. However, through the research and development of the tool, the importance of education became abundantly clear and is highly integrated throughout.

Several issues, characteristic to building certification and sustainability in the building industry in general, illuminated key components, which would become part of STAPLE in order to offer a guiding and supporting tool. One of the largest barriers to the use of DGNB is the complexity and understanding of the base material. STAPLE solves this by providing the user a breakdown of the primary elements of DGNB. The purpose of STAPLE is to facilitate the design process, encourage discussions, educate the user on various aspects of sustainability, and visually present the user input (opinion) from various project team members, which further promotes dialogue between the parties. A great deal of effort and time has been dedicated to the educational aspect of STAPLE. Explanations, directions, and guidelines have been added to each of the software sheets to help the user navigate through the tool. Many educational documents have been embedded into STAPLE as print-friendly PDF files. These are compactly formatted, abridged bite-sized summaries of various aspects of sustainability, breaking down information regarding DGNB in easy-to-read, easy-to-digest portions. Some documents overlap information from other documents to help the user see the 'red thread' of connectivity between concepts. Throughout the investigation, the information 
gathered has been presented in a simplified manner, providing the basics, useful links, and sources for further information, if desired. It is also worth noting, that the statement 'hover-over' or 'pop-up' comments, written for the laymen perspective, embedded into STAPLE, further supports the user understanding and is intended to provide the user with an overview of many different aspects of sustainability and the DGNB evaluation matrix through several 'digestible' pieces of information at a time. Besides promoting dialogue, one of the primary goals has been to change the perception of sustainability being an overwhelming and utterly complex topic by presenting the information in a simple and straightforward way piece by piece. Additionally, there are several other documents found in STAPLE, such as the Sustainability contract and the Criteria statement supplements. Based on the user feedback, the general response regarding the provided educational materials and user guides was largely positive with the majority of testers finding the information helpful, easy to read, and interesting.

As presented, STAPLE shall be considered a working prototype. It needs to be professionally upgraded to be more useful in the market. These upgrades would be to increase functionality to include beginner, intermediate, and advanced modes, improve the user's interface, include reporting capabilities, end reduce file size through cloud storage of PDFs. It is clear there is a market for a smaller, gentler version of DGNB for the much smaller projects. STAPLE, together with organizations like the Green Building Council Denmark, can accomplish a greater number of investors, buildings, designers, and owners being engaged, educated, and converted into using DGNB while developing high-performance quality buildings.

\section{ACKNOWLEDGEMENTS}

This paper became a reality with the kind help and support of many individuals. We would like to take the opportunity and extend our sincere thanks to all of them.

Foremost, we are grateful to the teaching staff at Aalborg University, whose expertise, understanding, guidance, and support made it possible for us to work on a topic that was of great interest to us.

We are highly indebted to the skilled professionals, who volunteered to test STAPLE throughout its various stages of development. Without their responsive and helpful feedback, STAPLE would have never advanced to where it is today.

We would like to express our gratitude to Hicham Johra, Aalborg University, whose feedback and guidance through the project left an invaluable impact on STAPLE and helped improve it beyond our own efforts.

We would also like to thank Gitte Gylling Hammershøj Olesen, Rambøll Aarhus, for her involvement, professional interest, and helpful feedback from the very beginning of this thesis.

We are also thankful to the adept and kind individuals, who, through informal conversations, support, and advice, helped shape this report. There are too many to name.

Our thanks and appreciations go out to everyone, who have willingly helped us with their knowledge.

\section{REFERENCES}

[1] Learn About Sustainability; United States Environmental Protection Agency Online. Available at: https://www.epa.gov/sustainability/learn-about-sustainability\#what. (Assessed 2 January 2017). 
[2] Why the building sector?; Architecture 2030, Santa FE Online. Available at: http:// architecture2030.org/buildings_problem_why/\#lightbox[group-158]/0/. (Assessed 2 January 2017).

[3] Danish Building Regulations 2015; The Danish Transport and Construction Agency Online. Available at: http://bygningsreglementet.dk/english/0/40. (Assessed 9 September 2016).

[4] The DGNB sustainability concept. The new quality of building; DGNB GmbH, Stuttgart, Deutschland Online. Available at: http://www.dgnb-system.de/en/system/dgnbsustainability_concept/. (Assessed 16 November 2016).

[5] An introduction to DGNB; Green Building Council Denmark (DK-GBC), Copenhagen, Denmark. Available at: http://dk-gbc.dk/media/2292/dgnb_dk-gbc_oct_2012.pdf. (Assessed 22 November 2016).

[6] Nielsen E., Statistics Denmark. Available at: http://www.statbank.dk/BYGV01. (Assessed 09 January 2017).

[7] Certified projects; Green Building Council Denmark (DK-GBC), Copenhagen, Denmark. Available at: http://www.dk-gbc.dk/dgnb/certificerede-projekter/. (Assessed 09 January 2017).

[8] Hankinson M. \& Breytenbach A., Barriers that impact on the implementation of sustainable design, Helsinki, Finland, 2012. Available at:http://www.unece.lsu.edu/ greenbuilding/documents/2013Mar/gb13_04.pdf. (Assessed 25 November 2016).

[9] Byggeri og anlæg; Statistics Denmark, Copenhagen, Denmark. Available at: http:// www.dst.dk/da/Statistik/emner/erhvervslivets-sektorer/byggeri-og-anlaeg. (Assessed 12 December 2016).

[10] Benefits for all; DGNB GmbH. Stuttgart, Deutschland. Available at: http://www. dgnb-system.de/en/certification/benefits/. (Accessed 16 November 2016).

[11] Brunsgaard, C., Knudstrup, M.A. \& Heiselberg, P.K., Experiences from the Design Processes of the First "Comfort Houses" in Denmark: Aalborg, 2009.

[12] Evaluation and awards; DGNB GmbH. Stuttgart, Deutschland. Available at: http:// www.dgnb-system.de/en/system/evaluation_and_awards/. (Assessed 12 December 2016).

[13] Saaty, T., How to make a decision: The Analytic Hierarchy Process (Report No.: 0377221), 1990. 